\title{
Myofibroblast Expression in Skin Wounds Is Enhanced by Collagen III Suppression
}

\author{
Mohammed M. Al-Qattan, ${ }^{1,2}$ Mervat M. Abd-Elwahed, ${ }^{2}$ Khalid Hawary, ${ }^{1}$ \\ Maha M. Arafah, ${ }^{3}$ and Medhat K. Shier ${ }^{2}$ \\ ${ }^{1}$ Department of Surgery, King Saud University, P.O. Box 18097, Riyadh 11415, Saudi Arabia \\ ${ }^{2}$ College of Medicine Research Center, King Saud University, P.O. Box 18097, Riyadh 11415, Saudi Arabia \\ ${ }^{3}$ Department of Pathology, King Saud University, Riyadh 11415, Saudi Arabia
}

Correspondence should be addressed to Mohammed M. Al-Qattan; moqattan@hotmail.com

Received 27 October 2014; Revised 6 February 2015; Accepted 7 February 2015

Academic Editor: Christian Schwentner

Copyright (C) 2015 Mohammed M. Al-Qattan et al. This is an open access article distributed under the Creative Commons Attribution License, which permits unrestricted use, distribution, and reproduction in any medium, provided the original work is properly cited.

\begin{abstract}
Generally speaking, the excessive expression of myofibroblasts is associated with excessive collagen production. One exception is seen in patients and animal models of Ehlers-Danlos syndrome type IV in which the COL3A1 gene mutation results in reduced collagen III but with concurrent increased myofibroblast expression. This paradox has not been examined with the use of external drugs/modalities to prevent hypertrophic scars. In this paper, we injected the rabbit ear wound model of hypertrophic scarring with two doses of a protein called nAG, which is known to reduce collagen expression and to suppress hypertrophic scarring in that animal model. The higher nAG dose was associated with significantly less collagen III expression and concurrent higher degree of myofibroblast expression. We concluded that collagen III content of the extracellular matrix may have a direct or an indirect effect on myofibroblast differentiation. However, further research is required to investigate the pathogenesis of this paradoxical phenomenon.
\end{abstract}

\section{Introduction}

In unwounded skin, fibroblasts are in a quiescent state within the extracellular matrix (ECM). Acute wounding results in changes in the microenvironment of the ECM (including the release of cytokines and growth factors) leading to the transformation of fibroblasts into myofibroblasts [1]. Myofibroblasts will have multiple functions such as collagen deposition and mediation of the cross talk within the ECM [2]. In primary wound healing, myofibroblasts undergo apoptosis after 2 weeks $[1,3]$. In wounds healing by secondary intention, myofibroblasts persist in the granulation tissue producing collagen and mediating wound contraction [3]. In pathological scarring such as scar hypertrophy and fibrotic conditions (such as scleroderma, pulmonary fibrosis, and Dupuytren's contracture), there is excessive expression of myofibroblasts and excessive production of collagen [1-3]. In other words, the excessive expression of myofibroblasts is almost always associated with excessive collagen deposition, and this is not surprising since myofibroblasts make and deposit collagen in the ECM. Ehlers-Danlos syndrome type IV (EDS IV, also known as the vascular type) is one exception. Patients with EDS IV have a mutation in the COL3A1 gene resulting in reduced amount of collagen III in their skin and other connective tissue such as the walls of the arteries and intestine. This results in areas of atrophic skin, easy bruising, aneurysms, and spontaneous visceral rupture $[4,5]$. However, patients with EDS IV are also known to develop postoperative scar hypertrophy [5] and spontaneous multiple skin keloid-like lesions [4]. Biopsies of these keloidal lesions show abnormal collagen (highly eosinophilic thick collagen bundles lying irregularly) with normal epidermis [4]. In contrast, biopsies of atrophic skin areas show epidermal atrophy, reduced collagen, loss of rote pegs, extravasation of red blood cells, and hemosiderin deposition in the dermis [4]. Mice models of EDS IV are heterozygous mutants known as 
the "Col III" mice" (since EDS IV in humans is autosomal dominant with heterozygous mutations). These mice have similar features to humans including reduced production of collagen III. Volk et al. [6] produced excisional wounds in Col $\mathrm{III}^{+/-}$mice and compared them to similar wounds in normal $\left(\mathrm{Col} \mathrm{III}{ }^{+/+}\right)$mice. Mutant mice had less collagen III but much more myofibroblast expression leading to accelerated wound contraction [6]. The authors could not explain this paradox and thought that further research is needed to investigate if other causes of collagen III deficiency will promote myofibroblast differentiation.

$\mathrm{nAG}$ is a salamander-derived protein mediating limb regeneration [7]. In a previous work in our lab, a new nAG gene (suitable for mammals) was designed and cloned. The cloned vector was transfected into primary human fibroblasts resulting in suppression of collagen expression [8]. In another communication we showed that daily local injections of recombinant $\mathrm{nAG}$ into the rabbit ear hypertrophic scar model results in lower scar elevation index (SEI) and lower collagen content [9]. Myofibroblast expression was not examined in our previous studies.

In the current paper, we injected rabbit ear wounds with two different doses of recombinant $\mathrm{nAG}$ and show that the degree of expression of myofibroblasts is inversely proportional to the degree of collagen III expression.

\section{Materials and Methods}

The experiment was approved by the Ethics Committee of the Medical College of our university.

2.1. Preparation of Recombinant $n A G$ and the Rabbit Ear Model. Details of synthesis and preparation of mammalian recombinant $\mathrm{nAG}$ protein was described in our previous work $[8,9]$. Mammalian recombinant nAG protein was synthesized by Genscript Company (Piscataway, NJ, USA) by using mammalian transient protein expression system (HEK 293-6E cells, mammalian expression rector pTT5). Individual doses (100 $\mathrm{nM}$ and $150 \mathrm{nM})$ were prepared and stored at $-80^{\circ} \mathrm{C}$.

The hypertrophic scar model in the rabbit ear is a wellestablished model in the literature $[10,11]$. A $7 \mathrm{~mm}$ punch biopsy is used to create a wound in the ear removing the epidermis, dermis, and perichondrium. The underlying cartilage acts as a splint to the wound edges and the wound epithelializes in 14 days. An established hypertrophic scar is known to appear at day 28. In studies (including our study) that aim to test the effect of a drug or a modality to decrease the formation of hypertrophic scars (i.e., prevention of scarring), the treatment is commenced at day 14 and wound scarring is assessed at day 28.

2.2. Surgical Procedure. Eight white New Zealand rabbits weighing $1.5-2 \mathrm{~kg}$ were used. The animals were anaesthetized with intramuscular ketamine $(40 \mathrm{mg} / \mathrm{kg}$ ) and xylazine $(4 \mathrm{mg}$ / $\mathrm{kg}$ ). One wound was created in each ear (one experimental and one control wound). A $7 \mathrm{~mm}$ punch biopsy was used to create the wound as described above. Wounds were dressed with normal saline-soaked gauze.

Wound injections were done daily starting at day 14 and ending at day 27. All control wounds $(n=8)$ were injected with $100 \mu \mathrm{L}$ of saline. Four experimental wounds were injected with $100 \mathrm{nM}$ of recombinant nAG (in $100 \mu \mathrm{L}$ of saline) and the other four experimental wounds were injected with $150 \mathrm{nM}$ of recombinant $\mathrm{nAG}$ (in $100 \mu \mathrm{L}$ of saline).

2.3. Assessment. Assessment was done in experimental and control wounds at day 28 after wounding. Three parameters were assessed: scar elevation index, histology, and quantitative determination of mRNA of collagen I and collagen III.

2.3.1. The Scar Elevation Index (SEI). SEI was previously described [12] and it represents the ratio of the scar tissue height to the normal tissue below the hypertrophic scar. A ratio of 1 indicates no difference in the wound area height compared with unwounded skin.

\subsubsection{Histological Analysis and Masson's Trichrome Staining.} Histological sections were fixed with $4 \%$ paraformaldehyde, embedded in paraffin, cut in $5 \mu \mathrm{m}$ sections, and stained with hematoxylin and eosin (H\&E). Masson's trichrome staining was done to stain collagen fibers.

2.3.3. Immunohistochemistry. Paraffin-embedded blocks of wounded skin specimens were cut into $3 \mu \mathrm{m}$ thick sections. The sections were mounted on saline coated slides and were incubated for 20 minutes in hot air oven at $60^{\circ} \mathrm{C}$. Tissue sections were deparaffinized with EZ Prep (Ventana, Arizona, USA) at $75^{\circ} \mathrm{C}$ and were heat-pretreated in Cell Conditioning 1 (CC1; Ventana, Arizona, USA) using "standard cell conditioning" for antigen retrieval at $100^{\circ} \mathrm{C}$, and then one drop of inhibitor solution was put for four minutes at $37^{\circ} \mathrm{C}$ and then tissue sections were washed. The slides were incubated 30 minutes at $37^{\circ} \mathrm{C}$ with diluted 1: 200 anti- $\alpha$-smooth muscle actin ( $\alpha$-SMA) or TGF $\beta 1$ monoclonal antibody (Abcam, UK). Then ultraview universal HRP multimer as secondary antibody was added. The immunostained proteins were visualized using a copper-enhanced DAB reaction. Immunostained sections were reviewed by Olympus BX51 light Microscope and DP72 Olympus Digital Camera (magnification 200x and 400x) (Olympus America Inc., Center Valley, PA, USA).

\subsubsection{Real Time PCR for Collagen mRNA Quantitation. RNA} was extracted from tissue samples using RNeasy Protect Mini Kit (Qiagen, Valencia, CA) and quantified by nanodrop. $100 \mathrm{ng}$ of total RNA was reverse-transcribed by using RotorGene Multiplex PCR Kit (Qiagen, Valencia, CA). Relative mRNA levels were calculated by using the $\Delta \Delta \mathrm{Ct}$ method and GAPDH as a reference gene. Primers and probes were mentioned in our previous published work [9]. Experiments were done three times at least.

2.4. Statistical Analysis. The SEI and RNA extraction data were expressed as mean \pm SD. The differences between the values of the two experimental groups (the $100 \mathrm{nM} \mathrm{nAG}$ 

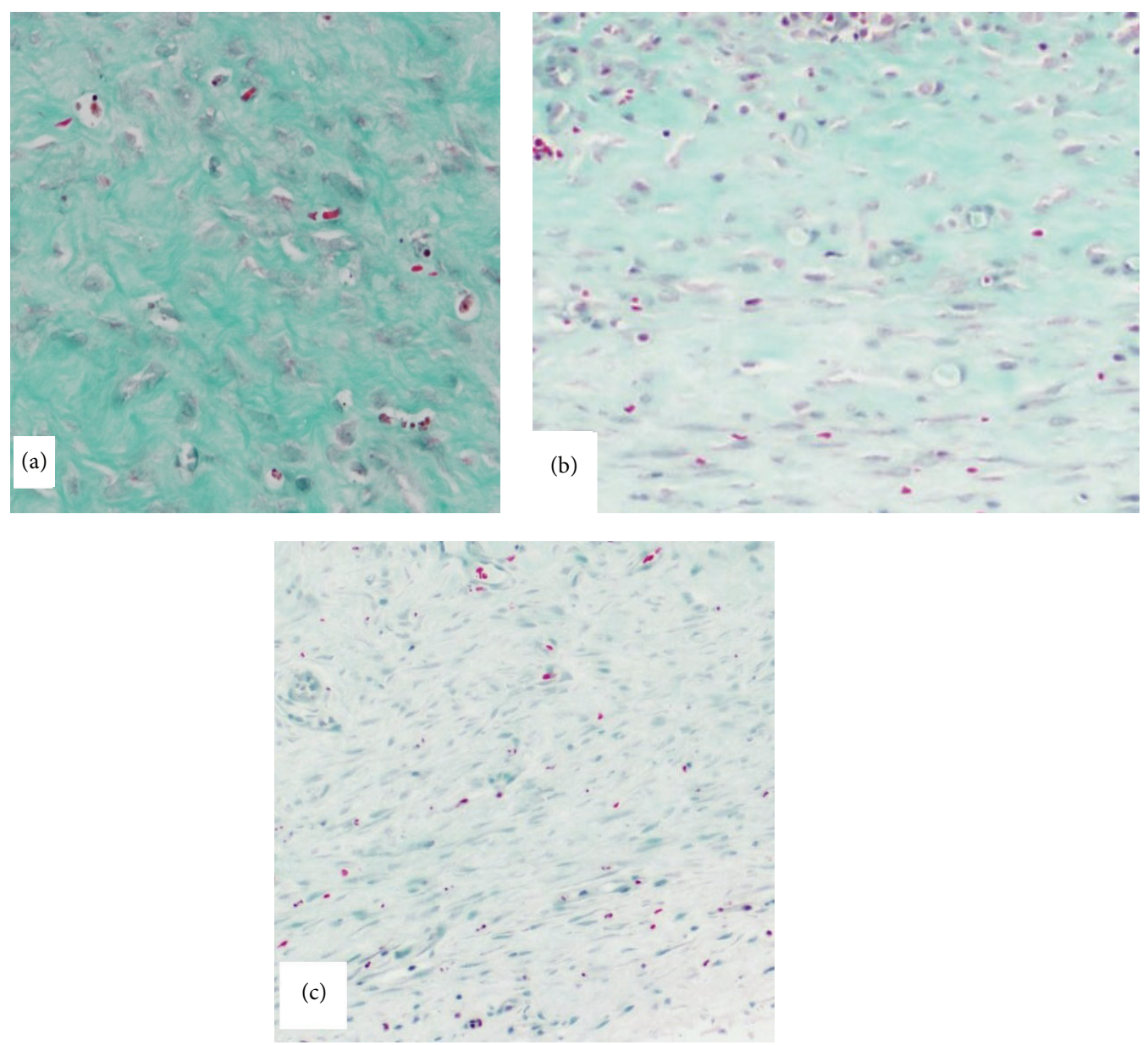

FIgURE 1: Masson's trichrome staining of the wound in the three groups. (a) A control wound showing thick, dense, and disorganized collagen fibers (magnification 40x). (b) An experimental $100 \mathrm{nM}$ nAG wound showing thin more regularly arranged collagen fibers with increased number of small blood vessels (magnification 40x). (c) An experimental $150 \mathrm{nM}$ nAG wound showing faint staining with sparse thin collagen bundles and increased vascularity (magnification 40x).

group and the $150 \mathrm{nM} \mathrm{nAG}$ group) as well as the control group (the saline without $\mathrm{nAG}$ group) were analyzed using the independent sample $t$-test (for SEI) and the MannWhitney test (for RNA extraction data). $P<0.05$ indicated a significant difference.

\section{Results}

At 28 days, the SEI of the control, the $100 \mathrm{nM} \mathrm{nAG}$, and the $150 \mathrm{nM}$ nAG groups were $1.37 \pm 0.08,1.19 \pm 0.05$, and $1.07 \pm$ 0.07 , respectively. The differences between the three groups were significant $(P<0.005)$. Masson's trichrome staining showed thick, dense, and disorganized collagen fibers in the control wounds (Figure 1(a)); thin more regularly arranged fibers with increased number of small blood vessels in the $100 \mathrm{nM}$ nAG experimental group (Figure 1(b)); and faint staining with sparse thin collagen bundles and increased vascularity in the $150 \mathrm{nM}$ nAG experimental group (Figure 1(c)). The vascularity in the $100 \mathrm{nM}$ nAG groups was more pronounced in the upper dermis, whereas it involved the entire dermis in the $150 \mathrm{nM}$ nAG group. $\alpha$-SMA stains both blood vessels and myofibroblasts. At 28 days after wounding, the control wound had minimal positive $\alpha$-SMA staining confined to the few dermal blood vessels (Figure 2(a)). The experimental $100 \mathrm{nM} \mathrm{nAG}$ group had moderate positive $\alpha$ SMA staining which was more pronounced in the upper dermis (Figure 2(b)). Finally, the experimental $150 \mathrm{nM}$ nAG group had intensely positive $\alpha$-SMA staining of the entire dermis (Figure 2(c)).

TGF $\beta 1$ immune staining showed relatively mild heterogeneous positivity in control wounds (Figure 3(a)), diffuse moderate positivity in the $100 \mathrm{nM}$ nAG group wounds (Figure 3(b)), and intense staining in the $150 \mathrm{nM}$ nAG group wounds (Figure 3(c)).

Compared to controls, the relative mRNA expression of collagen I and collagen III in both experimental groups is shown in Table 1 . Both experimental groups had significantly $(P<0.05)$ less collagen I and collagen III contents than controls. When the two experimental groups were compared to each other, there was no significant difference $(P>0.05)$ in collagen I content, but the high dose nAG group had 

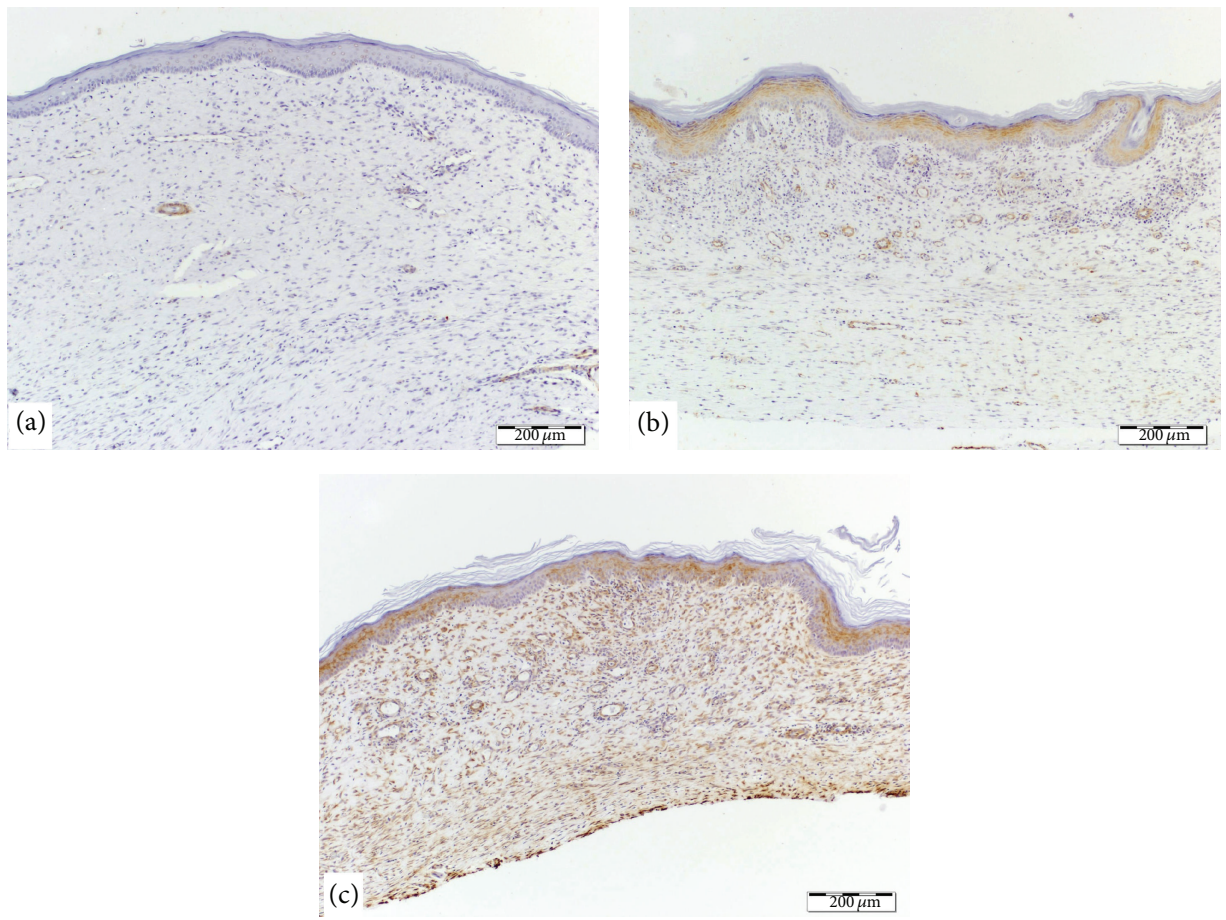

FIGURE 2: $\alpha$-smooth muscle actin stain (brown color) in the three groups. (a) A control wound showing minimal staining which is mainly confined to the few dermal blood vessels (magnification 10x). (b) An experimental $100 \mathrm{nM}$ nAG wound showing moderate staining which is more pronounced in the upper dermis (magnification 10x). (c) An experimental $150 \mathrm{nM} n \mathrm{nA}$ wound showing intense staining of the entire dermis (magnification 10x).
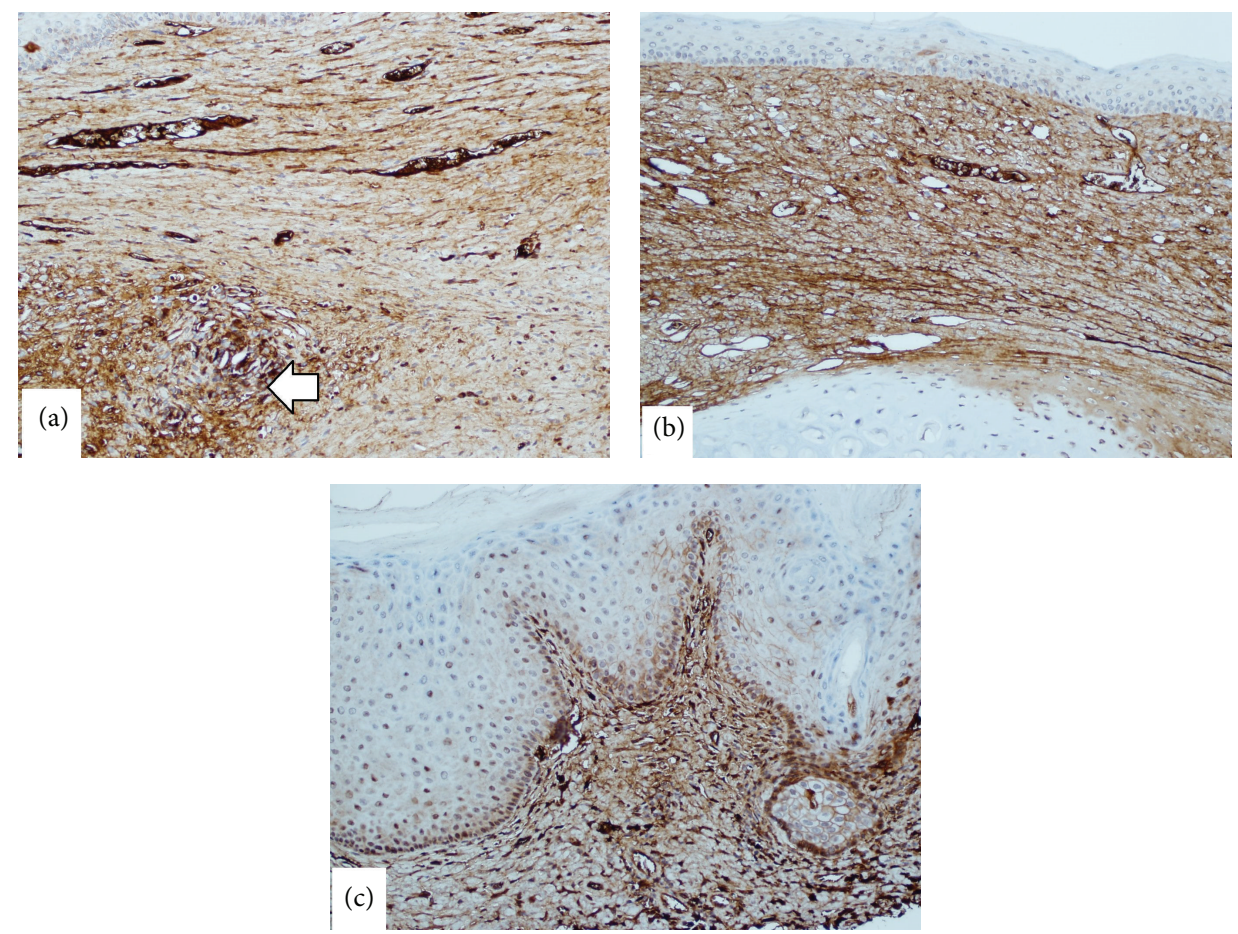

FIGURE 3: TGF $\beta 1$ immunohistochemical staining. (a) A control wound showing relatively mild heterogeneous positivity, although one focal area is more positive (arrow) (magnification 20x). (b) An experimental $100 \mathrm{nM} \mathrm{nAG}$ wound showing diffuse moderate staining indicating moderate positivity (magnification 20x). (c) An experimental $150 \mathrm{nM}$ nAG wound showing intense staining (magnification 20x). 
TABLE 1: "Relative" collagen I and collagen III contents in experimental groups compared to the control group (the collagen content in the control group is considered as 1).

\begin{tabular}{lcc}
\hline & $\begin{array}{c}\text { Relative collagen I } \\
\text { content }\end{array}$ & $\begin{array}{c}\text { Relative collagen III } \\
\text { content }\end{array}$ \\
\hline $\begin{array}{l}\text { Control } \\
\text { Low dose nAG } \\
\text { experimental group }\end{array}$ & 1 & 1 \\
$\begin{array}{l}\text { High dose nAG } \\
\text { experimental group }\end{array}$ & $0.16 \pm 0.06$ & $0.5 \pm 0.11$ \\
\hline
\end{tabular}

Both experimental groups had significantly $(P<0.05)$ less collagen I and collagen III contents than controls. When the two experimental groups were compared to each other, there was no significant difference $(P>0.05)$ in collagen I content but the high dose nAG group had significantly more collagen III suppression $(P<0.05)$ than the low dose nAG group.

significantly more collagen III suppression $(P<0.05)$ than the low dose $\mathrm{nAG}$ group.

\section{Discussion}

Our study showed the persistent high expression of myofibroblasts in wounds deficient in collagen. Both experimental groups had similar reductions of collagen I content. However, collagen III expression was most significantly reduced in the $150 \mathrm{nM}$ nAG group and this corresponded with the highest degree of myofibroblast expression. This indicates that it is the suppression of collagen III (and not collagen I) which induced the increased expression of myofibroblasts. Further research is required to investigate if this paradoxical phenomenon (low collagen III content with high myofibroblast expression) will also be seen with other modalities used to prevent hypertrophic scars.

The creation of a wound with very low collagen content and a high degree of myofibroblast expression is interesting from the scientific point of view. Myofibroblasts are known to have mature focal adhesions in their cell membrane [13 ]. These focal adhesions are complexes of many molecules including integrins and kinases. Myofibroblasts will not only produce collagen but can also "sense" tension in the ECM through these focal adhesions which act like receptors [2]. The most two important receptors mediating tension "sensing" and myofibroblast activity are the $\alpha \mathrm{V} \beta 3$ and $\alpha 5 \beta 1$ integrin receptors. Vitronectin binds mainly to $\alpha \mathrm{V} \beta 3$ receptors, whereas fibronectin binds mainly to $\alpha 5 \beta 1$ receptors [1-3]. Zoppi et al. [13] have shown that fibroblasts and myofibroblasts with COL $3 A 1$ gene mutations will not only produce less collagen III but will also recruit the $\alpha \mathrm{V} \beta 3$ instead of $\alpha 5 \beta 1$ integrin receptors. Hence, it is possible that the low collagen III expression in the ECM will have an effect on myofibroblasts through changes in the "tension" sensing receptors.

It is well known that TGF $\beta 1$ is the main stimulant of myofibroblast differentiation and stimulation of excessive collagen synthesis [14]. Our current study demonstrated the paradox of high myofibroblast expression in the presence of low collagen content. Hence, it seemed reasonable to study the expression of TGF $\beta 1$ within this paradoxical environment. Our study demonstrated that the intensity of TGF $\beta 1$ expression correlates with the intensity of myofibroblast expression. In our previous study [8] we showed that the suppressive effect of nAG on collagen synthesis is evident even with TGF $\beta 1$ stimulation. One possible explanation of the sequence of events in our model would be the primary suppression of collagen III by nAG. This may have caused a biofeedback mechanism through which TGF $\beta 1$ is stimulated, which will then stimulate myofibroblast differentiation. Since the $n A G$ effect on collagen is dominant over the TGF $\beta 1$ effect on collagen, collagen III remained low despite the high TGF $\beta 1$ expression.

Finally, our findings may have clinical relevance. For example, Dupuytren's cords are now being treated with direct injection of collagenase [15]. Collagenases will breakdown collagen within the cords and this allows the surgeon to break the cord by hyperextending the fingers [15]. Recurrence of cord contracture [16] and extensive deep tissue scarring [17] are well-known complications of this management approach. It is possible that the injection of collagenase will not only reduce the collagen content of the cord but will also induce myofibroblast expression leading to recurrence of contractures or deep-tissue scarring.

\section{Conclusion}

Myofibroblast expression in the rabbit ear model is enhanced by collagen III suppression. The pathogenesis of such a paradox needs further research but is clinically relevant.

\section{Ethical Approval}

Ethical approval was obtained from the Ethics Committee and the Animal Lab at the College of Medicine, King Saud University.

\section{Conflict of Interests}

The authors declare that they have no conflict of interests.

\section{Author's Contribution}

The senior author (Mohammed M. Al-Qattan) designed the experiment and supervised the work. The rest of the authors performed laboratory works. All authors contributed to the preparation of the paper.

\section{Acknowledgment}

The work was funded by the College of Medicine Research Center, Deanship of Scientific Research, King Saud University, Riyadh, Saudi Arabia.

\section{References}

[1] L. Van De Water, S. Varney, and J. J. Tomasek, "Mechano regulation of the myofibroblast in wound contraction, scarring 
and fibrosis; opportunities for new therapeutic intervention," Advances in Wound Care, vol. 2, no. 4, pp. 122-141, 2013.

[2] N. Vedrenne, B. Coulomb, A. Danigo, F. Bonté, and A. Desmoulière, "The complex dialogue between (myo)fibroblasts and the extracellular matrix during skin repair processes and ageing," Pathologie Biologie, vol. 60, no. 1, pp. 20-27, 2012.

[3] B. Hinz, "Formation and function of the myofibroblast during tissue repair," Journal of Investigative Dermatology, vol. 127, no. 3, pp. 526-537, 2007.

[4] N. L. Sharma, V. K. Mahajan, N. Gupta, N. Ranjan, and A. Lath, "Ehlers-Danlos syndrome-vascular type (ecchymotic variant): cutaneous and dermatopathologic features," Journal of Cutaneous Pathology, vol. 36, no. 4, pp. 486-492, 2009.

[5] D. P. Germain, "Ehlers-Danlos syndrome type IV," Orphanet Journal of Rare Diseases, vol. 2, no. 1, article 32, 2007.

[6] S. W. Volk, Y. Wang, E. A. Mauldin, K. W. Liechty, and S. L. Adams, "Diminished type III collagen promotes myofibroblast differentiation and increases scar deposition in cutaneous wound healing," Cells Tissues Organs, vol. 194, no. 1, pp. 25-37, 2011.

[7] A. Kumar, J. W. Godwin, P. B. Gates, A. A. Garza-Garcia, and J. P. Brockes, "Molecular basis for the nerve dependence of limb regeneration in an adult vertebrate," Science, vol. 318, no. 5851, pp. 772-777, 2007.

[8] M. M. Al-Qattan, M. K. Shier, M. M. Abd-Alwahed et al., "Salamander-derived, human-optimized nAG protein suppresses collagen synthesis and increases collagen degradation in primary human fibroblasts," BioMed Research International, vol. 2013, Article ID 384091, 9 pages, 2013.

[9] M. M. Al-Qattan, M. M. Abd-Al Wahed, K. Hawary, A. A. Alhumidi, and M. K. Shier, "Recombinant nAG (a salamanderderived protein) decreases the formation of hypertrophic scarring in the rabbit ear model," BioMed Research International, vol. 2014, Article ID 121098, 5 pages, 2014.

[10] E. Rahmani-Neishaboor, F. M.-K. Yau, R. Jalili, R. T. Kilani, and A. Ghahary, "Improvement of hypertrophic scarring by using topical anti-fibrogenic/anti-inflammatory factors in a rabbit ear model," Wound Repair and Regeneration, vol. 18, no. 4, pp. 401408, 2010.

[11] J. H. Ko, P. S. Kim, Y. Zhao, S. J. Hong, and T. A. Mustoe, "HMG-CoA reductase inhibitors (statins) reduce hypertrophic scar formation in a rabbit ear wounding model," Plastic and Reconstructive Surgery, vol. 129, no. 2, pp. 252e-261e, 2012.

[12] D. E. Morris, L. Wu, L. L. Zhao et al., "Acute and chronic animal models for excessive dermal scarring: quantitative studies," Plastic and Reconstructive Surgery, vol. 100, no. 3, pp. 674-681, 1997.

[13] N. Zoppi, R. Gardella, A. de Paepe, S. Barlati, and M. Colombi, "Human fibroblasts with mutations in COL5A1 and COL3A1 genes do not organize collagens and fibronectin in the extracellular matrix, down-regulate $\alpha_{2} \beta_{1}$ integrin, and recruit $\alpha_{v} \beta_{3}$ Instead of $\alpha_{5} \beta_{1}$ Integrin," The Journal of Biological Chemistry, vol. 279, no. 18, pp. 18157-18168, 2004.

[14] A. Biernacka, M. Dobaczewski, and N. G. Frangogiannis, "TGF$\beta$ signaling in fibrosis," Growth Factors, vol. 29, no. 5, pp. 196202, 2011.

[15] A. J. Watt, C. M. Curtin, and V. R. Hentz, "Collagenase injection as non-surgical treatment of Dupuytren's disease: 8-year followup," The Journal of Hand Surgery, vol. 35, no. 4, pp. 534-539, 2010.
[16] C. A. Peimer, P. Blazar, S. Coleman et al., "Dupuytren contracture recurrence following treatment with collagenase clostridium histolyticum (CORDLESS study): 3-year data," The Journal of Hand Surgery-American Volume, vol. 38, no. 1, pp. 12-22, 2013.

[17] W. M. Rozen, Y. Edirisinghe, and J. Crock, "Late complications of clinical Clostridium histolyticum collagenase use in Dupuytren's disease," PLoS ONE, vol. 7, no. 8, Article ID e43406, 2012. 


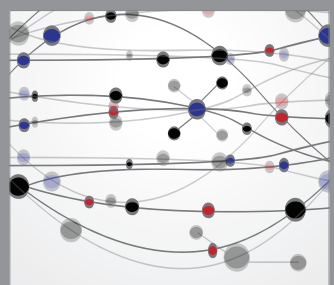

The Scientific World Journal
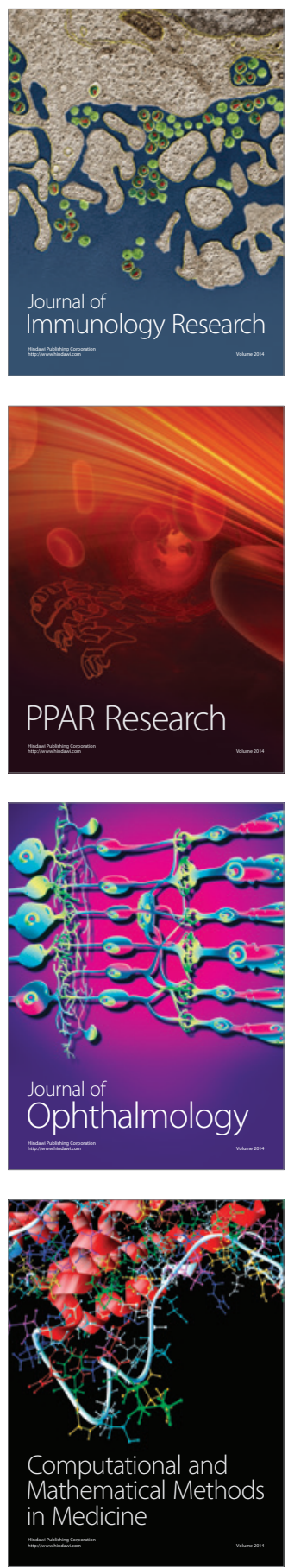

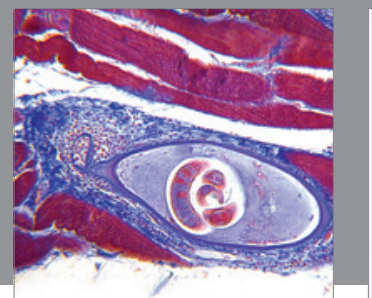

Gastroenterology

Research and Practice
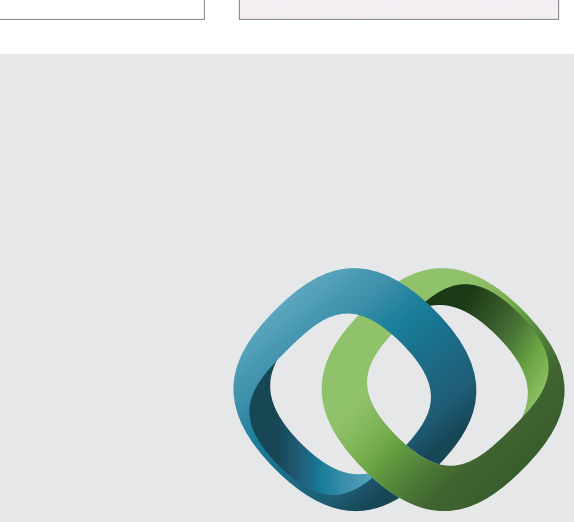

\section{Hindawi}

Submit your manuscripts at

http://www.hindawi.com
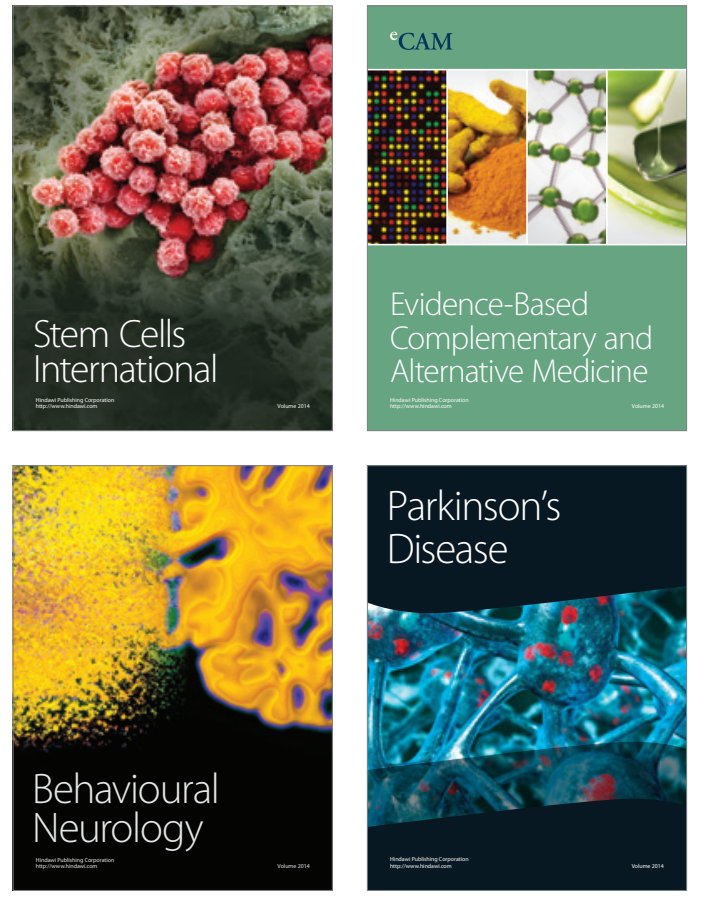
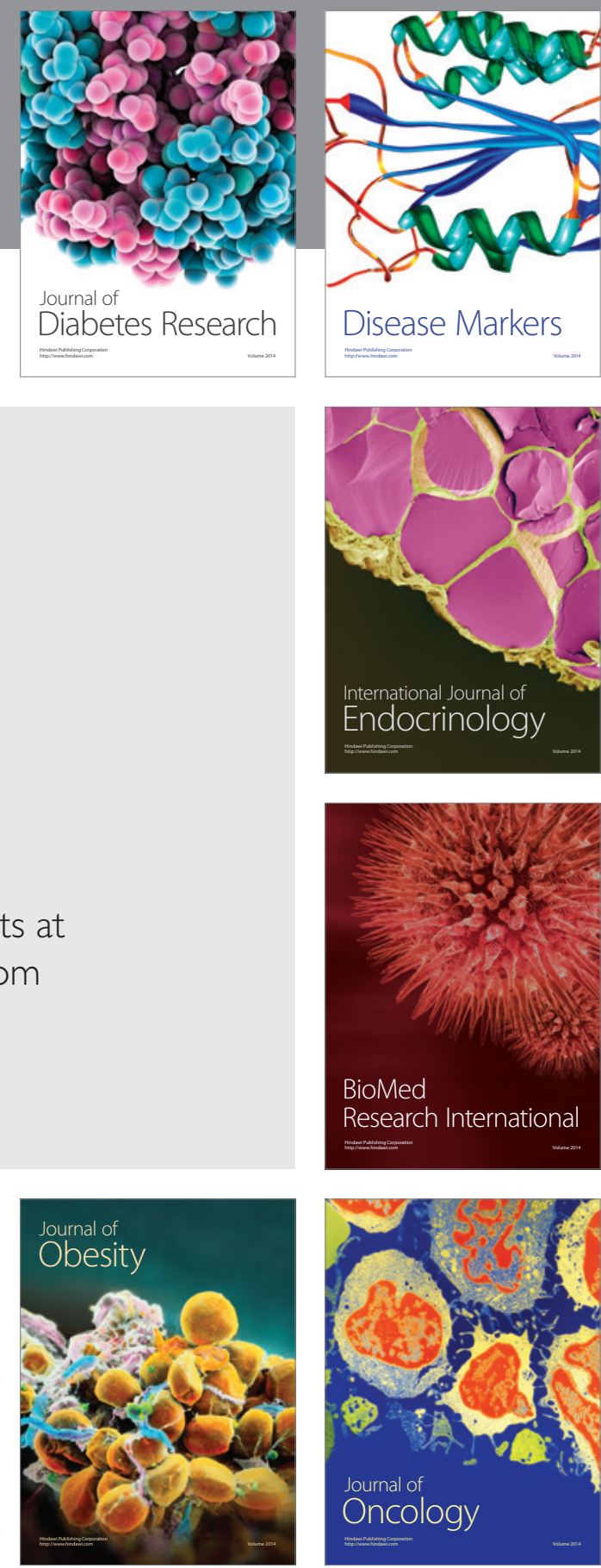

Disease Markers
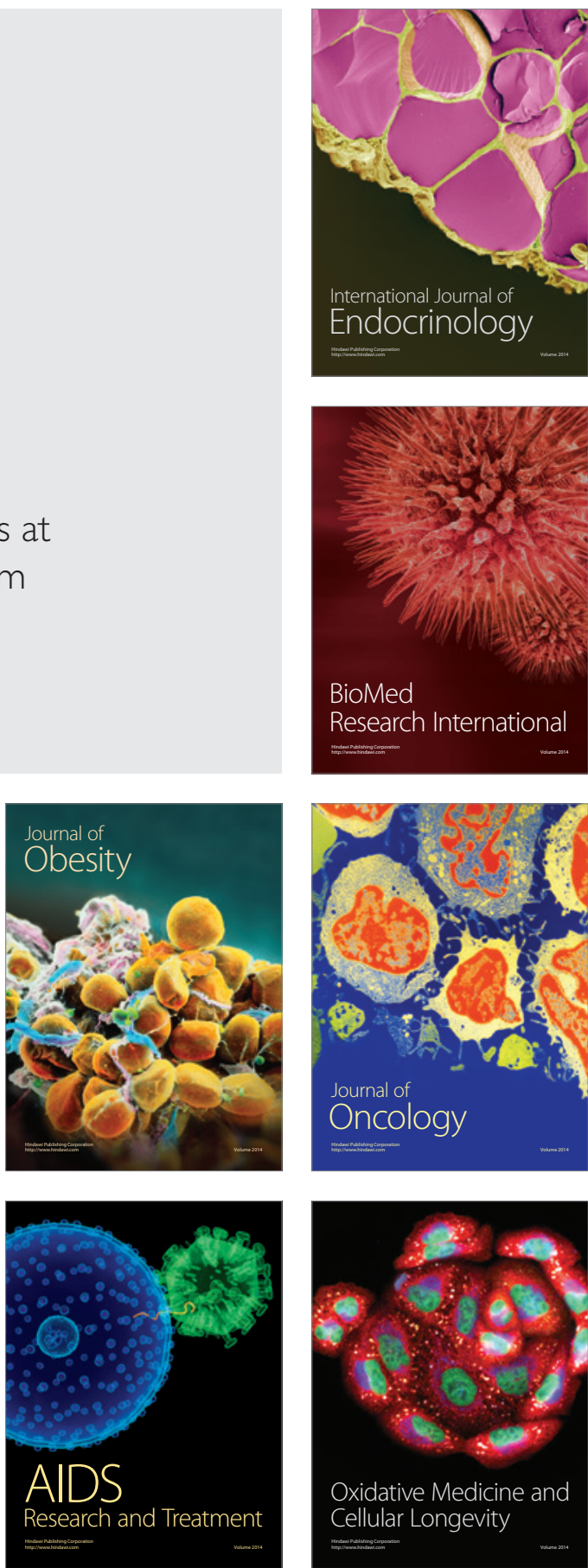